\title{
Racial/Ethnic Differences in Prosocial Beliefs and Prevention Behavior During the COVID-19 Pandemic
}

\author{
Heather Orom ${ }^{1}$ (D) - Natasha C. Allard ${ }^{1}$ (D) $\cdot$ Marc T. Kiviniemi $^{2}$ (D) Jennifer L. Hay ${ }^{3}$ (D) Erika A. Waters $^{4}$ (D) \\ Elizabeth Schofield ${ }^{3}$ (D) Sarah N. Thomas $^{4}$ (D) Malwina Tuman ${ }^{3}$ (D)
}

Received: 10 May 2021 / Revised: 7 July 2021 / Accepted: 18 July 2021 / Published online: 30 August 2021

(C) W. Montague Cobb-NMA Health Institute 2021

\begin{abstract}
Controlling the COVID-19 pandemic has required communities to engage in prosocial action, including behaviors that may inconvenience individuals, but protect the collective (e.g., mask wearing, social distancing). The purpose of this study was to understand to what extent COVID-19 prosocial beliefs and behavior differ by race/ethnicity and why this might be the case. A US nationally representative sample of 410 adults completed a survey about COVID-19 beliefs and prevention behaviors between June 12 and 18, 2020. Compared to White respondents, Black respondents perceived the risk of COVID-19 to be greater to the US population; and both Black and Latinx respondents thought it was more important to protect a variety of non-close others (e.g., people in their city or state). Black and Latinx respondents engaged in several prevention behaviors, including social distancing, to a greater extent than White respondents. There were indirect effects of Black vs. White race on engaging in protective behaviors through greater perceived risk to others and beliefs in the importance of protecting distal others. Results indicate that targeted messages promoting prevention, including vaccination with pro-social messages, may resonate with communities of color. They also suggest that lower levels of prosocial beliefs among White people have likely hindered the US response to the epidemic.
\end{abstract}

Keywords COVID-19 $\cdot$ Race/ethnicity $\cdot$ Black $\cdot$ Latinx/Hispanic $\cdot$ Prosocial $\cdot$ Prevention $\cdot$ Perceived risk

The COVID-19 pandemic has highlighted people's interconnectedness and the consequences that peoples' decision can have, not only for themselves, but for others. There have been well-publicized events where contagious individuals unknowingly spread COVID-19 by attending indoor events without masks, often resulting in dozens of cases, including deaths [1].
The pandemic has exposed a reluctance to elevate the needs of the collective to protect others as evidenced by vocal protest of mask and social distancing mandates. In July 2020, about $20 \%$ of people in the USA said they rarely or never wore a mask outside of their homes [2]. Without mass vaccination, mask wearing and social distancing are the primary strategies
Heather Orom

horom@buffalo.edu

Natasha C. Allard

Ncallard@buffalo.edu

Marc T. Kiviniemi

Marc.Kiviniemi@uky.edu

Jennifer L. Hay

hayj@mskcc.org

Erika A. Waters

waterse@wustl.edu

Elizabeth Schofield

schofiee@mskcc.org
Sarah N. Thomas

sarah.nicole.thomas@gmail.com

Malwina Tuman

tumanm@mskcc.org

1 Department of Community Health and Health Behavior, University at Buffalo, Buffalo, USA

2 Department of Health, Behavior and Society, University of Kentucky, Lexington, USA

3 Department of Psychiatry \& Behavioral Sciences, Memorial Sloan-Kettering Cancer Center, New York, USA

4 Washington University in St. Louis, St. Louis, USA 
available for controlling the spread of COVID-19. Because these behaviors protect others as well as the person engaging in the behavior, they have been described as prosocial [3]. In preparation for future pandemics and other outbreaks, we can study prosocial beliefs and behaviors in the context of COVID-19 to understand who may be more or less willing to engage in collective protective action and inform message framing to maximize effective with these audiences.

Reluctance to engage in behaviors that protect others as well as the self, including mask wearing and social distancing, may, in part, be due to American society having become less prosocial [4] and less empathic [5] over time. Being more prosocial, measured prior to the pandemic with a laboratory task that assesses peoples' decisions when self-interest and equity are at odds, predicted engaging in more COVID-19 prevention behaviors [6]. Similarly, people who were more empathic toward those most vulnerable to COVID-19 had greater intentions to physically distance and wear a mask and reported greater physical distancing, compared to people who were less empathic [7]. Similarly, empathy toward people in forced isolation during COVID-19 and general prosocial tendencies (tendency to engage in anonymous helping behavior) are associated with engaging in COVID-19 protective behaviors [3]. Selfishness, including selfish acts, egocentrism, and inflicting harm on other for self-gain are associated with lower engagement in COVID-19 protective behaviors [3]. Finally, message polarization by politicians [8] and the media [9] that frames prosocial behaviors as at odds with fundamental American values, such as individual freedoms, may have contributed to reluctance to engage in behaviors that protect others from COVID-19 (e.g., mask wearing, getting vaccinated).

Prosocial COVID-19 beliefs and prevention behaviors may differ by race/ethnicity. People who more strongly endorse collectivistic/communitarian rather than individualistic world views $[10,11]$, and Democrats compared to Republicans, have been more concerned about the risk of COVID-19 to society as a whole, more likely to endorse prevention measures, and more likely to engage in these behaviors [12-15]. Black and Latinx people are more likely to hold collectivist worldviews [16] and are more likely to be Democratic than Republican. In addition, it has been widely reported that Black and Latinx communities have suffered more during the pandemic than White communities. Awareness of differences in prevalence rates or accessibility of exemplars (availability heuristic) might contribute to perceptions of greater personal and collective vulnerability to COVID-19 among Black and Latinx people. Preliminary evidence indicates that people of color believe COVID-19 is a more significant threat to others and engaged in more prevention behaviors such as mask wearing. For example, in two waves of the nationally representative American Trends Survey (Pew Research Center) and a third sample from a national opt-in panel surveyed in
March 2020, minoritized groups perceived COVID-19 to not only be a greater risk to themselves but others as well $[17,18]$. In the two representative panels of the American Trends Survey, African American, Hispanic, and Asian respondents perceived the threat of COVID-19 to their health and the health of other Americans to be greater in 11 of 12 comparisons [17]. A second study reported consistent results using data from one of the two waves [16]. Respondents from the opt-in sample were asked what level of threat they thought COVID-19 posed to "individuals and their families," and overall fear of COVID-19. In three of six comparisons, people from minoritized groups had higher perceived risk and fear than White people [17]. Perceptions of COVID-19 risk to others are prosocial insofar as they are associated with willingness to engage in behaviors that prevent the spread of the disease. In a nationally representative sample surveyed between April and June 2020, Black and Latinx men and women and Asian men were also more likely to wear masks than Whites, and in particular, White men [19]. A second study also found that Latinx and Black people were more likely to engage in prevention behaviors than Whites [15].

With the present study, we sought to better understand racial/ethnic differences in COVID-19 prevention engagement by (1) more fully characterizing racial/ethnic differences in COVID-10 prosocial beliefs operationalized as perceived risk of COVID-19 to others and beliefs about the perceived importance of protecting others from COVID-19 and (2) seeking explanations for why there might be racial/ethnic differences in engaging in prevention behavior, including testing whether risk perceptions and beliefs about the importance of protecting others might help explain these behavioral differences. We hypothesized that perceptions of the risk of COVID-19 to others partly explain racial/ethnic differences in prevention behavior. We also engaged in a qualitative strategy to explore people's attributions about risk to generate additional hypotheses for beliefs potentially motivating racial/ethnic differences in prevention behavior.

\section{Methods}

\section{Participants and Procedure}

The study was a secondary analysis of a survey conducted by Ipsos, a leading market research firm. They administered a one-time survey to a representative sample of adults age 18 years or older living in the USA between June 12 and 18, 2020. Respondents were randomly selected from the Ipsos KnowledgePanel, the largest probability-based survey panel in the USA. The panel includes over 50,000 adults recruited via addressed-based sampling. Of 682 panel members invited to participate via KnowledgePanel, 410 completed the survey (completion rate of $60 \%$ ). The study sample included 291 
White, 36 Black, 46 Latinx respondents, and 37 identifying as another race. The make-up of the sample reflects the racial/ ethnic composition of the USA. Participants completed the survey online and were compensated with points they could exchange for rewards from Ipsos. The study was reviewed and determined exempt by the University of Kentucky Institutional Review Board.

\section{Measures}

Risk Perception We assessed participants' perceptions of the risk of developing COVID-19 for two referents: themselves and the average US person. For each, they were asked to rate four components of risk perception: absolute risk for getting COVID-19 ("How likely are you to get COVID-19 in the next 6 months? Very unlikely (1)-Very likely (4)"), gist-based feeling of the likelihood of infection ("How easily do you feel you could get COVID-19 in the next 6 months? Not at all easily (1)-Extremely easily (4)"), fear of getting COVID-19 ("How afraid are you of getting COVID-19 in the next 6 months? Not at all afraid (1)-Extremely afraid (4)"), and potential severity of the disease ("If you were to get COVID-19 in the next 6 months, how serious would it be? Not at all serious (1)-Extremely serious (4)"). Participants were also offered a "don't know option" for each question, but these data were not analyzed because the focus of this study was level of perceived risk. These questions were then repeated referring to the average US person instead of oneself. We created two composite perceived risk variables by calculating the mean of all four perceived risk for self-items $(\alpha=0.71)$ or all four perceived risk to others in the US items $(\alpha=0.84)$.

Reasons for Perceived Risk After rating their perceived risk, respondents indicated their risk using a scale response (i.e., did not select "I don't know") were asked what led them to answer the question the way they did, with the exception that 21 participants who responded "I don't know" to a question asking how certain they were about their response. These individuals were asked what had led them to answer "I don't know."

\section{Belief in the Importance of Protecting Close and Distal Others} Participants were given a list of 12 different groups (see Table 2) and asked, "How important is it to you to protect them from getting COVID-19?" on a four-point Likert-type scale where $1=$ not at all important and $4=$ extremely important. We created two composite variables: (a) belief in the importance of protecting distal others which was the mean ratings for coworkers, neighbors, people encountered when doing errands, people of own race, people of own political affiliation, and people in own community, own state, and own country, and (b) belief in the importance of protecting close others, which included the mean ratings for immediate family, extended family, and friends. Belief in the importance of protecting healthcare workers was excluded from the composite variables due to the distinct nature of this category and the nearly universal agreement that it is important to protect this group. An exploratory factor analysis with oblique rotation (promax) confirmed the dimensionality of these items and the two scales were internally consistent (distal other $\alpha=0.97$, close other $\alpha=0.92$ ).

Prevention Behaviors Respondents reported whether they had engaged in any of ten COVID-19 prevention behaviors derived from public health guidance at the time of the survey [20-22] in the previous 7 days (see Table 3 ) by responding "yes" or "no" to each behavior. The behaviors reflect Centers for Disease Control and Prevention (CDC) guidance at the time of the study and are very similar to behaviors assessed in other COVID-19 surveys [3, 23]. In addition to examining behaviors separately, we calculated a composite variable by summing the number of behaviors each participant had performed.

Demographics Demographic variables included age, marital status (married or cohabitating vs. single/divorced/widowed), race/ethnicity (non-Latinx White, non-Latinx Black, Latinx, another race), highest education level ( $<$ high school, high school, some college, $\geq$ bachelor's degree), household income (21 incremental categories), and degree of urbanization (living in a metropolitan statistical area (MSA) vs. outside an MSA).

\section{Data Analysis}

Quantitative Analysis We applied post-stratification weights benchmarked to the most recent American Community Survey for all analyses except the free responses. We used linear and logistic regression models to test associations between race/ethnicity (the predictor), and the three kinds of outcomes: perceived COVID-19 risk, perceived importance of protecting others, and COVID-19 protective behavior. In each model, we adjusted for the demographic variables that were significantly associated with race/ethniciy $(p<0.05)$ and therefore potential confounders. These were education level and household income, entered as continuous variables, and a dichotomous variable indicating whether participants lived in an MSA. There was no multicollinearity among these variables or with the predictor (VIFs $<1.4)$. We estimated indirect effects to explore whether perceived risk of COVID-19 to others, and belief in the importance of protecting distal or close others partially accounted for racial/ethnic differences in engaging in prevention behaviors. To accomplish this, we used structural equation modeling (SEM) commands to estimate the indirect effects of Black vs. White and Latinx vs. White race/ethnicity on the total number of prevention behaviors through (1) perceived risk to others, (2) belief in the 
importance of protecting distal others, and (3) belief in the importance of protecting close others. We estimated each of the three indirect effects separately and controlled for perceived personal risk but not demographic characteristics to keep models parsimonious due to the small size of the Black and Latinx samples. There were very low rates of missing data; the highest rate for any variable was $1.0 \%(n=5)$. Model testing involved listwise deletion. We conducted quantitative analyses using Stata version 16.1 (Stata Corp., College Station, TX).

Qualitative Analysis We identified categories of responses to the open-ended question about their reasons for one's level of perceived absolute risk by open coding a subset of responses. Codes were refined through an iterative process of expanding and collapsing codes to yield 8 codes and an "other" category. More than one code could be applied to a given participant's response. Two authors independently coded all the statements, interrater-reliability was estimated with Cohen's kappa $(k>$ 0.92 ) and discrepancies were resolved through consensus. When frequencies of responses are reported, these are unweighted as only about two-thirds of the sample provided responses.

\section{Results}

Weighted sample demographics are provided in Table 1. These reflect the demographics of the non-institutionalized adult US population. Education level (Black $\mathrm{B}=-0.47$, $95 \% \mathrm{CI}=-0.92,-0.02, p=0.043$; Latinx $\mathrm{B}=-0.85$, $95 \% \mathrm{CI}=-1.19,-0.51, p<0.001)$, household income $($ Black $\mathrm{B}=-0.49,95 \% \mathrm{CI}=-2.24,1.25, p=0.578$; Latinx $\mathrm{B}=-2.07,95 \% \mathrm{CI}=-3.87,-0.27, p=0.025)$ and whether participants lived in an MSA (Black OR $=8.25,95 \%$ $\mathrm{CI}=1.09,62.71, p=0.041$; Latinx $\mathrm{OR}=6.18,95 \% \mathrm{CI}=1.42$, $26.92, p=0.015)$ were significantly associated with race/ethnicity. Gender, age, and marital status were not, $p<$ 0.05 .

Race/Ethnicity and Risk Perception Figure 1 shows adjusted associations between Black vs. White race/ethnicity (panel A) and Latinx vs. White race/ethnicity (panel B) and respondents' risk perceptions. Compared to White respondents, Black respondents generally perceived the risk of others getting COVID-19 to be higher. This was not the case for perceived risk to self. Only one of the four outcomes (absolute risk to others) was significantly higher for Latinx compared to White respondents.

Race/Ethnicity and Protection of Other Groups In adjusted models, compared to White respondents, Black and Latinx respondents thought it was more important to protect several
Table 1 Participant demographics c

\begin{tabular}{|c|c|}
\hline Demographic characteristic & Weighted \% \\
\hline \multicolumn{2}{|l|}{ Race/ethnicity } \\
\hline Non-Latinx White & 63.14 \\
\hline Non-Latinx Black & 11.82 \\
\hline Latinx & 16.44 \\
\hline Another race & 8.59 \\
\hline \multicolumn{2}{|l|}{ Household annual income } \\
\hline$<\$ 25 \mathrm{k}$ & 13.56 \\
\hline$\$ 25 \mathrm{k}$ to $<\$ 50 \mathrm{k}$ & 18.19 \\
\hline$\$ 50 \mathrm{k}$ to $<\$ 75 \mathrm{k}$ & 17.21 \\
\hline$\$ 75 \mathrm{k}$ to $<\$ 100 \mathrm{k}$ & 13.74 \\
\hline$\$ 100 \mathrm{k}$ to $<\$ 150 \mathrm{k}$ & 17.70 \\
\hline$\$ 150 \mathrm{k}$ and up & 19.61 \\
\hline \multicolumn{2}{|l|}{ Education } \\
\hline$<$ High school & 10.60 \\
\hline High school graduate & 28.31 \\
\hline Some college & 27.77 \\
\hline$\geq$ Bachelor's degree & 33.32 \\
\hline \multicolumn{2}{|l|}{ Age } \\
\hline $18-29$ & 20.90 \\
\hline $30-44$ & 25.13 \\
\hline $45-59$ & 24.69 \\
\hline $60+$ & 29.28 \\
\hline \multicolumn{2}{|l|}{ Gender } \\
\hline Female & 51.59 \\
\hline Male & 48.41 \\
\hline Married or cohabitating & 60.96 \\
\hline \multicolumn{2}{|l|}{ Urbanization } \\
\hline Metropolitan area & 13.34 \\
\hline Non-metropolitan area & 86.66 \\
\hline
\end{tabular}

Note. Income and education were entered as continuous variables in multivariable models

groups of others from developing COVID-19. In general, Black respondents were more motivated to protect both close $(b=0.25,95 \% \mathrm{CI}=0.04,0.47, p=0.020)$ and $\operatorname{distal}(b=0.61$, $95 \% \mathrm{CI}=0.37,0.85, p<0.000$ ) others from COVID-19 than Whites. Latinx respondents were more motivated to protect distal $(b=0.36,95 \% \mathrm{CI}=0.02,0.70, p=0.039)$ but not close $(b=0.15,95 \% \mathrm{CI}=-0.19,0.49, p=0.391)$ others compared to Whites. The effects were reliable across many different target groups (see Table 2).

Race/Ethnicity and Prevention Behavior In adjusted models, there were no COVID-19 prevention behaviors less likely to be reported by Black or Latinx respondents than White respondents (Table 3). Controlling for education, income, and rurality, Black respondents were more likely than White respondents to encourage family to stay home $(b$ 
A. Adjusted Perceived COVID-19 Risk to Self and Others in Black Compared to White Respondents

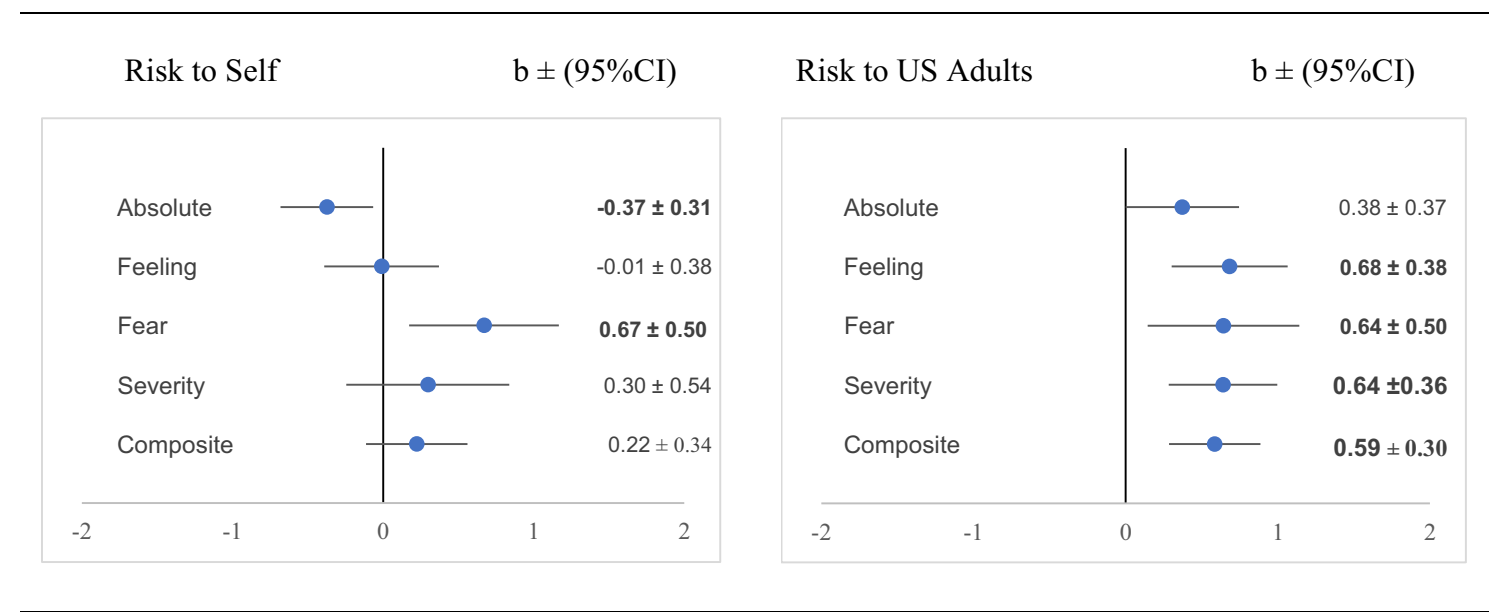

B. Adjusted Perceived COVID-19 Risk to Self and Others in Latinx Compared to White Respondents

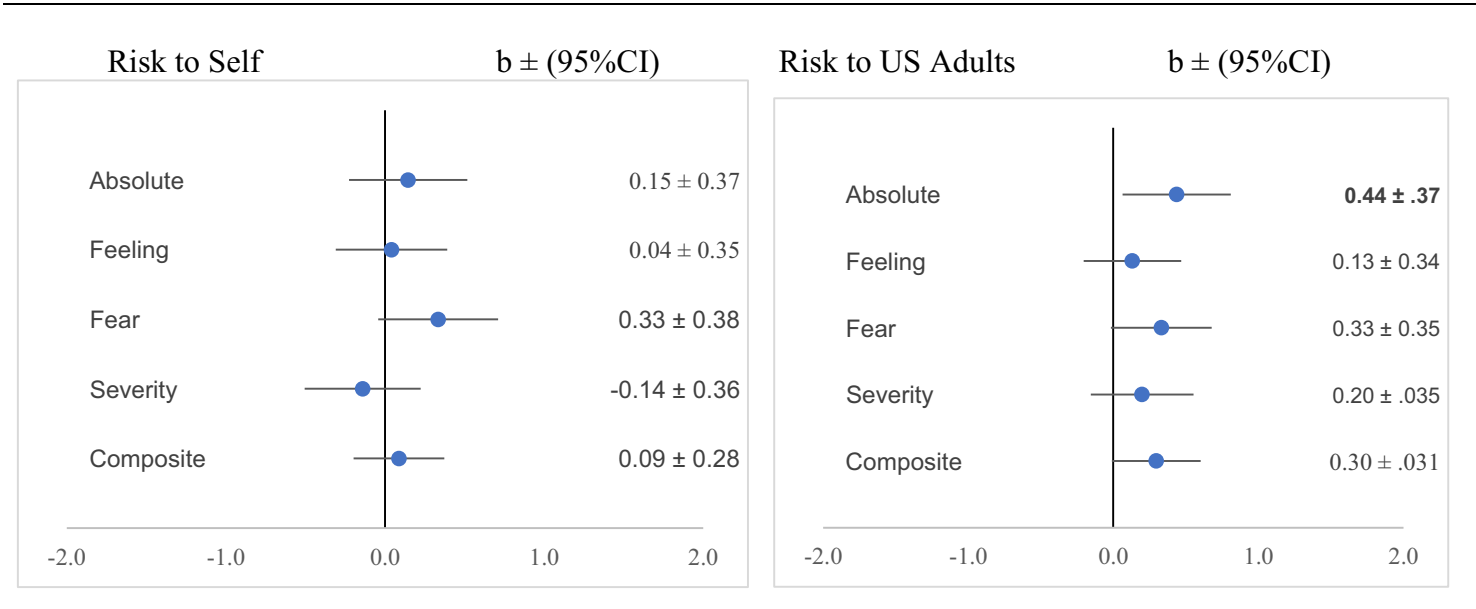

Fig. 1 Associations between race/ethnicity and risk perception. A Adjusted perceived COVID-19 risk to self and others in Black compared to White respondents. B Adjusted perceived COVID-19 risk to self and others in Latinx compared to White respondents. Note. Composite perceived risk is the mean score for the four perceived risk components. Each

$=0.25,95 \% \mathrm{CI}=0.09,0.42, p=0.002)$, avoid visiting with others in person $(b=0.18,95 \% \mathrm{CI}=0.01,0.34, p=$ $0.035)$, and avoid touching their face $(b=0.19,95 \% \mathrm{CI}=$ $0.02,0.36, p=0.024)$. Latinx respondents were more likely than White respondents to avoid in-person work $(b=0.20,95 \% \mathrm{CI}=0.03,0.38, p=0.025)$, avoid touching their face $(b=0.19,95 \% \mathrm{CI}=0.03,0.34, p=0.017)$, and encourage family to stay home $(b=0.35,95 \% \mathrm{CI}=$ $0.21,0.49, p<0.000)$. Latinx $(b=1.22,95 \% \mathrm{CI}=0.13$, $2.31, p=0.028)$ respondents reported more prevention behaviors overall than Whites.

Are There Indirect Effects of Race/Ethnicity on Prevention Behaviors Through Perceived Risk to Others and Concern for Others? The indirect effects of Black vs. White and Latinx relation between race/ethnicity and perceived risk was tested in a separate linear regression model controlling for education, income, and living in an MSA. Bolding indicates a statistically significant effect $p<.05$.

vs. White race/ethnicity on COVID-19 prevention behaviors through (a) perceived risk of COVID-19 to others and belief in the importance of protecting (b) distal others and (c) close others are presented in Table 4. The table also includes the direct effects of race/ethnicity on prevention behavior, total effects, the ratio of indirect to direct effects, and percent of total effect mediated. Controlling for perceived risk to self, Black vs. White race/ethnicity had an indirect effect on total number of prevention behaviors through the composite measure of perceived risk to others. The indirect effect for Latinx vs. White was not statistically significant $(p=0.06)$. There was an indirect effect of Black vs. White race/ethnicity on total number of prevention behaviors through the composite measure of belief in the importance of protecting distal others but not close others. Indirect effects for Latinx vs. White race/ 
Table 2 Racial/ethnic differences in mean (SD) perceived importance of protecting others

\begin{tabular}{lllll}
\hline Others to Protect & Race/ethnicity & & & \\
\hline & Black & Latinx & White & Overall \\
Immediate family (e.g., parents, children, spouse/partner) & $3.7(0.5)$ & $3.6(0.8)$ & $3.5(0.8)$ & $3.5(0.8)$ \\
Extended family & $3.6(0.6)^{* *}$ & $3.5(0.8)$ & $3.3(0.8)$ & $3.4(0.8)$ \\
Close friends & $3.6(0.6)^{*}$ & $3.4(0.9)$ & $3.3(0.8)$ & $3.4(0.8)$ \\
Coworkers or classmates & $3.5(0.8)^{* *}$ & $3.4(0.8)^{*}$ & $3.0(0.9)$ & $3.2(0.9)$ \\
Neighbors & $3.7(0.5)^{* * *}$ & $3.4(0.9)$ & $3.0(0.9)$ & $3.2(0.9)$ \\
People you encounter when doing shopping or errands & $3.5(0.5)^{* * *}$ & $3.3(1.0)$ & $3.0(0.9)$ & $3.2(0.9)$ \\
People of your race/ethnicity & $3.6(0.6)^{* * *}$ & $3.3(0.9)^{* *}$ & $2.8(1.0)$ & $3.0(1.0)$ \\
People with shared political values & $3.3(0.9)^{* * *}$ & $3.1(1.1)$ & $2.7(1.1)$ & $2.7(1.1)$ \\
People in your city or community & $3.7(0.6)^{* * *}$ & $3.4(0.9)$ & $3.0(0.9)$ & $3.2(0.9)$ \\
People in your state & $3.5(0.7)^{* * *}$ & $3.4(0.9)$ & $3.0(0.9)$ & $3.1(0.9)$ \\
People who live in the USA & $3.7(0.6)^{* * *}$ & $3.4(0.8)$ & $3.0(0.9)$ & $3.2(0.8)$ \\
Healthcare workers & $3.7(0.6)$ & $3.6(0.8)$ & $3.5(0.7)$ & $3.5(0.7)$ \\
All close others & $3.6(0.6)^{*}$ & $3.5(0.8)$ & $3.4(0.8)$ & $3.4(0.7)$ \\
All distal others & $3.6(0.6)^{* * *}$ & $3.3(0.8)^{*}$ & $3.0(0.8)$ & $3.1(0.8)$ \\
\hline
\end{tabular}

Note. The table presents observed means and standard deviations; however, tests of differences are based on adjusted regression models. We tested separate regression models for each target "other" group. Models included education, income, and living in an MSA. Significant differences between Black and Latinx compared to White respondents are denoted $* p<0.05 ; * * p<0.01 ; * * * p<0.001$ ethnicity on prevention behavior through belief in the importance of protecting distal others and close others were not statistically significant.

Reasons for Level of Perceived Risk Most respondents ( $n=$ $273,66.59 \%$ ) gave a response when asked why they perceived their risk for COVID-19 the way they did. Table 5 includes the categories of responses, examples, and prevalence of these responses in the total sample of Black, Latinx, and White respondents. Overall, the most common reasons people appraised their risk as they did was because they were engaging in prevention behaviors. No Black respondents attributed their risk to being healthy or having a strong immune system, whereas Latinx $(4.35 \%)$ and White $(4.47 \%)$ respondents did. Latinx respondents $(13.04 \%)$ believed they had additional exposure risk at work compared to $2.78 \%$ of Black and $3.44 \%$ of White respondents. Other responses could apply to perceptions of risk to others as well as oneself. While relatively
Table 3 Percent of sample engaging in prevention behaviors

\begin{tabular}{lllll}
\hline Prevention behavior & \multicolumn{2}{l}{ Race/ethnicity } & & \\
\cline { 2 - 5 } & Black & Latinx & White & Overall \\
\hline Wear mask & 93.71 & 92.54 & 82.76 & 86.31 \\
Encourage family to stay home & $79.10^{* *}$ & $88.41^{* * *}$ & 54.23 & 63.46 \\
Avoid visiting with others in person & $77.13^{*}$ & 73.98 & 59.35 & 64.67 \\
Avoid public transit & 86.89 & 89.50 & 76.28 & 81.01 \\
Avoid grocery shopping & 35.61 & 43.05 & 32.58 & 36.20 \\
Avoid in-person work & 52.63 & $67.64 *$ & 53.78 & 55.99 \\
Avoid touching face & $79.04 *$ & $79.70 *$ & 56.08 & 63.25 \\
Disinfect surfaces & 84.93 & 89.40 & 73.90 & 76.42 \\
Use hand sanitizer & 90.09 & 89.31 & 86.39 & 87.74 \\
Wash hands & 90.09 & 96.11 & 100.00 & 98.05 \\
Mean (SD) count of total behaviors (out of 10) & $7.67(2.68)$ & $7.95(2.63) *$ & $6.73(2.30)$ & $7.09(2.42)$ \\
\hline
\end{tabular}

Note. Percentages are observed; however, statistically significant differences are based on adjusted regression models. We tested separate regression modes for each behavior. Models included education, income, and living in an MSA. Significant differences between Black and Latinx compared to White respondents are denoted $* p<0.05$, $* * p<0.01, * * * p<0.001$ 
uncommon, $5.50 \%$ or 16 White respondents said that the pandemic was over overblown, a hoax or less serious than portrayed. No Black respondents mentioned this as a reason for their risk perception. Only White respondents (5.84\%) thought that where they lived lowered their risk.

\section{Discussion}

The first key finding from this study is that that people who identified as Black or Latinx had more prosocial COVID-19 beliefs than people who identified as White. Specifically, compared to White respondents, Black respondents perceived the risk of COVID-19 to be greater to others and both Black and Latinx respondents thought it was more important to protect groups of non-close others (e.g., people who live in your city and state). The roots of Black-White differences in prosocial beliefs may, in part, stem from more prosocial and collectivist worldviews because of Black people's involvement in civil rights struggles and greater engagement in church and working in the public sector [24]. The differences may also have an underlying logic similar to the White (and Asian) male effect - a robust pattern where some White and Asian men express less concern about a range of threats to society such as technology, climate change and other environmental threats, guns, and crime [25-27]. In general, the effect has been attributed to privilege - the men are thought to perceive the threat to be lower because they have more control and resources that would allow them to personally mitigate the threat [28]. There is evidence the effect is driven by men who are conservative [26] and who hold more individualistic and hierarchical world views which are inconsistent with collective action to address social threats, especially threats that may disproportionately affect people with less privilege [29]. Similar to the White male effect, White respondents may perceive the risk of COVID-19 to be lower because they fail to appreciate the lack of control other communities have had over spread of the virus. In a larger sample, one might explore whether there are subgroups such as conservative White men who are driving the differences observed in this study.

The second key finding of the study is that more Black and Latinx respondents engaged in several of the prevention behaviors than White respondents; engagement in these behaviors may, in part, be attributable to perceiving others to be at greater risk for COVID-19 and greater belief in the importance of protecting others. In line with the hypothesis that Black and Latinx people responded more pro-socially to the pandemic, one of these differences was for social distancing, which protects oneself and others. In addition, free responses to being asked why they appraised their personal risk as they did also shed light on reasons White people may not have been as concerned about the impact of COVID-19 on others as Black and Latinx people. Whereas the responses were 
Table 5 Types of reasons given for COVID-19 risk perception by race/ethnicity

\begin{tabular}{|c|c|c|c|c|}
\hline \multirow[t]{2}{*}{ Category } & \multirow[t]{2}{*}{ Example } & \multicolumn{3}{|c|}{ Percent who mentioned $(n)$} \\
\hline & & Black & Latinx & White \\
\hline Social distancing & I rarely leave home & $30.56(11)$ & $28.26(13)$ & $34.02(99)$ \\
\hline Other/general prevention & I wear a mask when outside & $36.11(13)$ & $23.91(11)$ & $31.62(92)$ \\
\hline Employment exposure & I'm a frontline worker & $2.78(1)$ & $13.04(6)$ & $3.44(10)$ \\
\hline Infection inevitable & It is bound to happen at some point no matter how careful a person is & $0.00(0)$ & $10.87(5)$ & $7.90(23)$ \\
\hline Live in area with low prevalence & $\begin{array}{l}\text { Because I live in Montana and we are already in phase two. } \\
\text { We have very few if not any cases in Montana now }\end{array}$ & $0.00(0)$ & $0.00(0)$ & $5.84(17)$ \\
\hline Healthy person & I have good immune system & $0.00(0)$ & $4.35(2)$ & $4.47(13)$ \\
\hline Already infected & Because I already had it, so I believe I am immune now & $2.78(1)$ & $0.00(0)$ & $2.06(6)$ \\
\hline Overblown & It's not real & $0.00(0)$ & $2.17(1)$ & $5.50(16)$ \\
\hline Other & Not sure what is true & $5.56(2)$ & $4.35(2)$ & $7.56(22)$ \\
\hline
\end{tabular}

uncommon among people of color, some White respondents said that COVID-19 was overblown, and others said they lived in a region or community with low prevalence. At the time of the data collection, these respondents may in fact have belonged to communities that were less affected by the pandemic; however, believing that its severity was overblown reflects a reluctance to appreciate the higher rates of infection, morbidity, and mortality in communities of color. White privilege involves a failure to recognize the advantages people experience because of their position in a racially hierarchical society [30].

Results for Latinx respondents were less consistent than for Black respondents. As a group, Latinx are racially, socioeconomically, linguistically, and culturally diverse. Collapsing across this diversity could obscure patterns in some groups that do not emerge in others. Future research might attempt to disaggregate trends within Latinx groups based on national origin or socioeconomic status.

Because risk perception is typically heightened when people can quickly think of exemplars affected by the illness (availability heuristic), having had COVID-19 and/or knowing more individuals who have had serious COVID-19 disease increases perceptions of risk [31, 32]. Given national racial/ethnic disparities in incidence and mortality at the time, we expected both rates of having had COVID-19 and number of people in social network who had the illness to be greater among Black and Latinx respondents than Whites; however, this was not the case in our sample. Perhaps people currently dealing with COVID-19 in their households or social networks were less likely to participate in the survey. Nonetheless, the larger presence of COVID-19 in Black and Latinx communities at the time the data were collected may have heighted perceptions of risk of the disease to others.

Another finding that might have been surprising was that Latinx respondents reported the highest rate of avoiding inperson work, and the difference between Latinx and White respondents was statically significant. Latinx respondents were also the most likely to mention that being a frontline worker contributed to their risk for getting COVID-19, which is consistent with national data indicating that Latinx individuals are much more likely than White and Asian individuals, and only slightly less likely than Black individuals, to hold frontline jobs [33]. We suspect that this seeming contradiction is due to Latinx individuals being among the most likely to have employment involving necessary interactions with others, thus making them the most likely to try to avoid this kind of exposure.

Relevance to communication campaigns. Throughout the COVID-19 pandemic, public health officials have called for the public to engage in prevention behaviors for the sake of others [34]. While all racial/ethnic groups in this study felt the need to protect those close to them, Black and Latinx respondents were more likely to feel protective towards more distant community members or groups. This is welcome news that could be applied to targeting COVID-19 vaccination campaigns, as targeted messages are often more effective than non-targeted messages [35]. Findings that COVID-19 prevention messages were found to be less effective when pro-social targets were distant others [36-38] may not apply to audiences of color. The present study demonstrates specific audiences (Black, Latinx) for which community-oriented prosocial messages may in fact be effective at modifying COVID-19 intentions and behaviors. Studying people's behavior in the context of COVID-19 has helped us learn ways of promoting prosocial behavior. For example, exemplifying generous acts by regular people, such as coming out of retirement to serve as part of the COVID-19 healthcare workforce, encourages others to engage in prosocial behavior. In contrast, exemplifying selfish COVID-19 behavior such as people's failure to follow social distancing mandates does the opposite [31]. The researchers reasoned that when people trust that others will also be generous, they are more willing to act in the interest 
of the group. Another strategy is coupling positive emotional arousal with prosocial messages to also increase their persuasiveness [39]. Similarly, whereas risk information alone may not motivate prevention behavior, combining it with an affective empathic appeal to protect a vulnerable individual appears to do so [7].

\section{Strengths and limitations}

The study sample was representative of the US population, but it was relatively small. For this reason, we were only able to compare responses from Black, Latinx, and White participants. Nevertheless, through a variety of measures and both quantitative and qualitative data, we were able to triangulate a key finding: during the COVID-19 pandemic, people who self-identified as Black, and to a less extent Latinx, emerged as more prosocial in both their beliefs and behavior compared to Whites. While we sought to help explain relations between cognitions and behavior, the reported associations cannot be assumed to be causal. We were not able to directly rule out whether awareness of racial inequities in COVID-19 incidence and mortality was influencing people's perceptions of risk, either among people of color who knew the threat to be greater in their communities or Whites who perceived the risk to be lower by comparison. Importantly, controlling for the number of people respondents knew who had COVID-19 did not alter the findings. Our nomothetic approach to classifying other groups as close or distal might have obscured individual or group differences in perceived closeness of the target groups. Future work might incorporate an idiographic approach where respondents are able to classify groups with respect to closeness prior to grouping them for analysis. Additional future research directions include testing the effectiveness of pandemic response messages framed to emphasize prosocial beliefs in Black and Latinx communities. Basic science may focus greater attention on the underpinnings and consequences of racial/ethnic differences in prosocial beliefs and behavior outside of the context of COVID-19.

\section{Conclusion}

The impact of the pandemic has been more devastating to Black and Brown communities than White communities. As of March 2021, Black, Latinx, and Indigenous people in the USA were about two times more likely to have died of COVID-19 [40]. At the time the data for the study were collected for this study, the gap was even wider, with Black people over three and a half times more likely and Latinx people two and a half times more likely to have died from the illness [41]. In the first half of 2020, life expectancy in the USA dropped 2.7 years for Black people and 1.9 years for Latinx people, com- pared to dropping only 0.8 years for Whites [42]. These racial/ ethnic inequities are due, in large part, to historical and presentday structural racism (public and institutional policies and practices that create or reinforce racial inequity) [43]. Structural racism, for example, created segregated neighborhoods where deleterious social determinants of health have given rise to the illnesses that make people vulnerable to serious COVID-19 disease [44] and is associated with greater incidence and mortality for Black and Latinx residents [45, 46]. Lack of economic and educational opportunity (forms of systemic racism) has resulted in Black and Latinx people being overrepresented in high-risk essential worker jobs and jobs where they could not work from home [47, 48]. Structural racism in the form of less access to high-quality healthcare [49] may also have exacerbated mortality rates. For people of color, structural racism and COVID-19 were a syndemic epidemic-co-occurring epidemics that interacted synergistically to increase incidence and mortality rates [50].

Lower concern about COVID-19, especially in the early months of the pandemic before it spread to all communities in the USA, including rural communities, was a White privilege. This is a combination of willful ignorance of the realities facing people of color and the additional burden they were and would bear from the spread of COVID-19. It is part of a history of White people being complicit through accepting and sometimes benefitting from the systemic inequalities such as systems of housing, financial, and healthcare segregation that have robbed communities of color of influence and investment that contributed to COVID-19 inequities.

Authors' Contributions Heather Orom, Jennifer Hay, Marc Kiviniemi, and Erika Waters were responsible for the conceptualization of the study; Marc Kiviniemi was responsible for financially supporting data collection; Natasha Allard, Heather Orom, and Elizabeth Schofield were responsible for the data analysis; Heather Orom and Natasha Allard drafted the manuscript; all authors contributed to editing the draft manuscript.

Funding Data collection was supported by the Development Dimensions International Endowed Professorship Fund (MTK)

Data availability Data are available upon request from the corresponding author.

Code Availability Syntax are available upon request from the corresponding author.

\section{Declarations}

Ethics Approval The study was approved by the University of Kentucky institutional review board.

Consent to Participate Participants were part of a standing IPSOS survey panel. IPSOS conducts an overall consent process when participants join the panel. 
Conflict of Interest The authors declare no conflict of interest.

\section{References}

1. Lewis D. Superspreading drives the COVID pandemic - and could help to tame it. Nature. 2021;590(7847):544-6. https://doi.org/10. 1038/d41586-021-00460-x.

2. Brenan M. Americans' face mask usage varies greatly by demographics. In: Gallup. 2020. https://news.gallup.com/poll/315590/ americans-face-mask-usage-varies-greatly-demographics.aspx. Accessed 1 Apr 2021.

3. Dinić BM, Bodroža B. COVID-19 protective behaviors are forms of prosocial and unselfish behaviors. Front Psychol. 2021;12(1128). https://doi.org/10.3389/fpsyg.2021.647710.

4. Hampton KN. Why is helping behavior declining in the United States but not in Canada?: Ethnic diversity, new technologies, and other explanations. City Community. 2016;15(4):380-99. https:// doi.org/10.1111/cico.12206.

5. Konrath SH, O'Brien EH, Hsing C. Changes in dispositional empathy in American College students over time: a meta-analysis. Personal Soc Psychol Rev. 2011;15(2):180-98. https://doi.org/10. $1177 / 1088868310377395$.

6. Campos-Mercade P, Meier AN, Schneider FH, Wengström E. Prosociality predicts health behaviors during the COVID-19 pandemic. J Public Econ. 2021;195:104367. https://doi.org/10.1016/j. jpubeco.2021.104367.

7. Pfattheicher S, Nockur L, Böhm R, Sassenrath C, Petersen MB. The emotional path to action: Empathy promotes physical distancing and wearing of face masks during the COVID-19 pandemic. Psychol Sci. 2020;31(11):1363-73. https://doi.org/10.1177/ 0956797620964422 .

8. Green J, Edgerton J, Naftel D, Shoub K, Cranmer SJ. Elusive consensus: polarization in elite communication on the COVID-19 pandemic. Sci Adv. 2020;6(28):eabc2717. https://doi.org/10.1126/ sciadv.abc2717.

9. Hart PS, Chinn S, Soroka S. Politicization and polarization in COVID-19 news coverage. Sci Commun. 2020;42(5):679-97. https://doi.org/10.1177/1075547020950735.

10. Savadori L, Lauriola M. Risk perception and protective behaviors during the rise of the COVID-19 outbreak in Italy. Front Psychol. 2020;11. https://doi.org/10.3389/fpsyg.2020.577331.

11. Dryhurst S, Schneider CR, Kerr J, Freeman AL, Recchia G, Van Der Bles AM, et al. Risk perceptions of COVID-19 around the world. J Risk Res. 2020;23(7-8):994-1006. https://doi.org/10. 1080/13669877.2020.1758193.

12. Allcott H, Boxell L, Conway J, Gentzkow M, Thaler M, Yang D. Polarization and public health: Partisan differences in social distancing during the coronavirus pandemic. J Public Econ. 2020;191:104254. https://doi.org/10.1016/j.jpubeco.2020.104254.

13. Callow MA, Callow DD, Smith C. Older adults' intention to socially isolate once COVID-19 stay-at-home orders are replaced with "Safer-at-Home" public health advisories: a survey of respondents in Maryland. J Appl Gerontol. 2020;39(11):1175-83. https:// doi.org/10.1177/0733464820944704.

14. Masters NB, Shih S-F, Bukoff A, Akel KB, Kobayashi LC, Miller $\mathrm{AL}$, et al. Social distancing in response to the novel coronavirus (COVID-19) in the United States. PLoS One. 2020;15(9): e0239025. https://doi.org/10.1371/journal.pone.0239025.

15. Bruine de Bruin W, Saw HW, Goldman DP. Political polarization in US residents' COVID-19 risk perceptions, policy preferences, and protective behaviors. J Risk Uncertain. 2020:1-18; https://doi. org/10.1007/s11166-020-09336-3

16. Chen X, Orom H, Kiviniemi MT, Waters EA, Schofield E, Li Y, et al. Cultural worldviews and perceived risk of colon cancer and diabetes. Health Risk Soc. 2020;22(5-6):324-45. https://doi.org/10. 1080/13698575.2020.1827142

17. Shao W, Hao F. Confidence in political leaders can slant risk perceptions of COVID-19 in a highly polarized environment. Soc Sci Med. 2020;261:113235. https://doi.org/10.1016/j.socscimed.2020. 113235.

18. Niño M, Harris C, Drawve G, Fitzpatrick KM. Race and ethnicity, gender, and age on perceived threats and fear of COVID-19: evidence from two national data sources. SSM Popul Health. 2021;13: 100717. https://doi.org/10.1016/j.ssmph.2020.100717.

19. Hearne BN, Nino MD. Understanding how race, ethnicity, and gender shape mask-wearing adherence during the COVID-19 pandemic: evidence from the COVID impact survey. J Racial Ethn Health Disparities. 2021. https://doi.org/10.1007/s40615-02000941-1.

20. How to protect yourself \& others. In: Centers for Disease Control and Prevention. 2020. https://www.cdc.gov/coronavirus/2019ncov/prevent-getting-sick/prevention.html. Accessed 24 July 2020.

21. Team Kentucky coronavirus home page. In: Kentucky Public Health. 2020. https://govstatus.egov.com/kycovid19. Accessed 24 July 2020.

22. How to prepare and protect yourself. In: Taskforce WHC. https:// www.coronavirus.gov. Accessed 24 July 2020.

23. Magnan RE, Gibson LP, Bryan AD. Cognitive and affective risk beliefs and their association with protective health behavior in response to the novel health threat of COVID-19. J Behav Med. 2021;44(3):285-95. https://doi.org/10.1007/s10865-021-00202-4.

24. Gumber C, Padavic I. Race differences in motivations for joining unions: the role of prosocial beliefs. Soc Sci Q. 2020;101(2):490502. https://doi.org/10.1111/ssqu.12772.

25. Palmer C. Risk perception: another look at the 'white male' effect. Health Risk Soc. 2003;5(1):71-83. https://doi.org/10.1080/ 1369857031000066014.

26. McCright AM, Dunlap RE. Cool dudes: the denial of climate change among conservative white males in the United States. Glob Environ Chang. 2011;21(4):1163-72. https://doi.org/10. 1016/j.gloenvcha.2011.06.003.

27. Finucane ML, Slovic P, Mertz CK, Flynn J, Satterfield TA. Gender, race, and perceived risk: the 'white male' effect. Health Risk Soc. 2000;2(2):159-72. https://doi.org/10.1080/713670162.

28. Olofsson A, Rashid S. The white (male) effect and risk perception: can equality make a difference? Risk Anal. 2011;31:1016-32. https://doi.org/10.1111/j.1539-6924.2010.01566.x.

29. Kahan DM, Braman D, Gastil J, Slovic P, Mertz CK. Culture and identity-protective cognition: explaining the white-male effect in risk perception. J Empir Leg Stud. 2007;4(3):465-505. https://doi. org/10.1111/j.1740-1461.2007.00097.x.

30. McIntosh P. White privilege: unpacking the invisible knapsack. Understanding prejudice and discrimination. New York, NY, US: McGraw-Hill; 2003. p. 191-6.

31. Abel M, Brown W. Prosocial behavior in the time of COVID-19: the effect of private and public role models. IZA Discussion Paper No. 13207. 2020; https://ssrn.com/abstract=3596673

32. Guastafierro E, Toppo C, Magnani FG, Romano R, Facchini C, Campioni R, et al. Older adults' risk perception during the COVID-19 pandemic in lombardy region of Italy: a crosssectional curvey. J Gerontol Soc Work. 2021;64:1-14. https://doi. org/10.1080/01634372.2020.1870606.

33. Casura L, Lowe R, Jr, Martinez C, Serpas S, Castellanos V, Singelmann J. Frontline workers in the U.S.: Race, ethnicity, and gender. In: N-IUSSP. 2020. https://www.niussp.org/article/ frontline-workers-in-the-u-s-race-ethnicity/. Accessed 1 March 2021.

34. Cheng KK, Lam TH, Leung CC. Wearing face masks in the community during the COVID-19 pandemic: altruism and solidarity. 
Lancet. 2020:S0140-6736(20)30918-1; https://doi.org/10.1016/ S0140-6736(20)30918-1

35. Noar SM, Benac CN, Harris MS. Does tailoring matter? Metaanalytic review of tailored print health behavior change interventions. Psychol Bull. 2007;133(4):673-93. https://doi.org/10.1037/ 0033-2909.133.4.673.

36. Banker S, Park J. Evaluating prosocial COVID-19 messaging frames: evidence from a field study on Facebook. Judgm Decis Mak. 2020;15(6):1037-43.

37. $\mathrm{Ma} \mathrm{H}$, Miller $\mathrm{CH}$. The effects of agency assignment and reference point on responses to COVID-19 messages. Health Commun. 2021;36(1):59-73. https://doi.org/10.1080/10410236.2020. 1848066.

38. Yu N, Shen F. Benefits for me or risks for others: a cross-culture investigation of the cffects of message frames and cultural appeals. Health Commun. 2013;28(2):133-45. https://doi.org/10.1080/ 10410236.2012.662147.

39. Heffner J, Vives M-L, FeldmanHall O. Emotional responses to prosocial messages increase willingness to self-isolate during the COVID-19 pandemic. Personal Individ Differ. 2021;170:110420. https://doi.org/10.1016/j.paid.2020.110420.

40. (CDC) CfDCaP. Risk for COVID-19 infection, hospitalization, and death by race/ethnicity. In: Center for Disease Control and Prevention (CDC) Data and Surveillance. 2021. https://www.cdc. gov/coronavirus/2019-ncov/covid-data/investigations-discovery/ hospitalization-death-by-race-ethnicity.html. Accessed 6 March 2021.

41. Ford T, Reber S, Reeves R. Race gaps in COVID-19 deaths are even bigger than they appear. In: Brookings. 2020. https://www. brookings.edu/blog/up-front/2020/06/16/race-gaps-in-covid-19deaths-are-even-bigger-than-they-appear/. Accessed 6 March 2021.

42. Arias E, Tejada-Vera B, Ahmad F. Provisional life expectancy estimates for January through June, 2020. Hyattsville, MD; 2021. 10.15620/cdc: 100392
43. Marrett CB. Racial disparities and COVID-19: The social context. J Racial Ethn Health Disparities. 2021;8(3):794-7. https://doi.org/10. 1007/s40615-021-00988-8

44. Richardson J, Mitchell B, Meier H, Lynch E, Edlebi J. Redlining and neighborhood health. Washington, DC: National Community Reinvestment Coalition (NCRC); 2021. https://ncrc.org/holchealth/

45. Torrats-Espinosa G. Using machine learning to estimate the effect of racial segregation on COVID-19 mortality in the United States. Proc Natl Acad Sci. 2021;118(7):e2015577118. https://doi.org/10. 1073/pnas.2015577118.

46. Yu Q, Salvador CE, Melani I, Berg MK, Neblett EW, Kitayama S. Racial residential segregation and economic disparity jointly exacerbate COVID-19 fatality in large American cities. Ann N Y Acad Sci. 2021;1494:18-30. https://doi.org/10.1111/nyas.14567.

47. Selden T, Berdahl T. COVID-19 and racial/ethnic disparities in health risk, employment, and household composition. Health Aff. 2020;39(9):1624-32. https://doi.org/10.1377/hlthaff.2020.00897.

48. Rogers TN, Rogers CR, VanSant-Webb E, Gu LY, Yan B, Qeadan F. Racial disparities in COVID-19 mortality among essential workers in the United States. World Medical \& Health Policy. 2020;12(3):311-27. https://doi.org/10.1002/wmh3.358.

49. Douglas JA, Subica AM. COVID-19 treatment resource disparities and social disadvantage in New York City. Prev Med. 2020;141: 106282. https://doi.org/10.1016/j.ypmed.2020.106282.

50. Poteat T, Millett GA, Nelson LE, Beyrer C. Understanding COVID-19 risks and vulnerabilities among black communities in America: the lethal force of syndemics. Ann Epidemiol. 2020;47: 1-3. https://doi.org/10.1016/j.annepidem.2020.05.004.

Publisher's Note Springer Nature remains neutral with regard to jurisdictional claims in published maps and institutional affiliations. 